\title{
Electrochemical Dechlorination of Chlorobenzene in Acetonitrile with Various Water Concentrations
}

\author{
Nagahiro HosHI,* Akihiro HAGA, and Yoshio HORI
}

\begin{abstract}
Department of Applied Chemistry and Biotechnology, Faculty of Engineering, Chiba University (1-33, Yayoi-cho, Inage-ku, Chiba 263-8522, Japan)
\end{abstract}

Received June 30, 2004 ; Accepted September 13, 2004

\begin{abstract}
Electrochemical reduction of chlorobenzene has been studied on a silver polycrystalline electrode in acetonitrile solution containing various concentrations of water. The main product is benzene. The partial current density of benzene $j_{\mathrm{C} 6 \mathrm{H} 6}$ is enhanced with the increase of the concentration of chlorobenzene linearly. The value of $j_{\mathrm{C} 6 \mathrm{H} 6}$ is independent of the concentration of water. This result differs from the electrolysis of chloroform in which the partial current density of the product (methane) is enlarged with the increase of the water concentration remarkably. The electrolysis in acetonitrile containing $\mathrm{D}_{2} \mathrm{O}$ shows that the proton source of benzene is acetonitrile as well as water.
\end{abstract}

Key Words : Dechlorination of Chlorobenzene, Benzene, Silver Electrode, Water Concentration

\section{Introduction}

Electrolysis in organic solvents can reduce organic halides with high current density at room temperature and under ambient pressure. ${ }^{1-3}$ The residue of water in organic solvents sometimes plays an important role as a proton source in the reduction: the water in acetonitrile enhances the reduction rate of chloroform $\left(\mathrm{CHCl}_{3}\right)$ to methane $\left(\mathrm{CH}_{i}\right)$ on silver electrode remarkably. High concentration of water also prevents the formation of an insulating film on the electrode.

Chlorobenzene forms the framework of noxious aromatic chloride such as dioxin and polychlorobiphenyl (PCB). The study of the dechlorination of chlorobenzene will contribute to new technologies for the decomposition of dioxin and PCB. The electrochemistry of chlorobenzene has been studied widely using voltammetry and polarography. ${ }^{5,6)}$ Few papers, however, have reported the electrolysis of chlorobenzene. ${ }^{7.8}$ The main product of the electrolysis is benzene. There has been no report concerning the effects of water on the electrolysis of chlorobenzene. Electrochemical reduction of iodobenzene to benzene was studied in organic solvents containing $\mathrm{D}_{2} \mathrm{O}$ for revealing the proton source of the deiodonation: water is the main proton source. ${ }^{9,10)}$ Saveant studied the isotope effect on the electrolysis of the aromatic organic halides, and showed that the proton source depends on the chemical species to be reduced. ${ }^{11)}$ In this communication, we report the effect of residue of water on the rate of the dechlorination of chlorobenzene on polycrystalline silver electrode.

\section{Experimental}

Silver wire for the working electrode was etched using nitric acid. Counter electrode was platinum wire. $\mathrm{Ag} / \mathrm{Ag}^{+}$ electrode ( $0.01 \mathrm{M} \mathrm{AgNO}_{3}$ in acetonitrile) was used as a reference electrode. The electrode potential was corrected using the redox potential of ferrocene $\left(\mathrm{Fc} / \mathrm{Fc}^{+}\right)$.
Ormic drop of the potential was compensated with a potential compensator (Hokuto Denko, HI-203). The electrolysis cell consists of a single compartment.

Special grade acetonitrile (Wako) was further purified by distillation. The electrolyte, tetraethylammonium perchlorate (TEAP: $\left.\left(\mathrm{C}_{2} \mathrm{H}_{5}\right)_{4} \mathrm{NClO}_{4}\right)$, was purified by recrystallization. Chlorobenzene was purchased from Aldrich and used as received. Water concentration was controlled by the addition of ultrapure water or $\mathrm{D}_{2} \mathrm{O}$ (Nakarai, 99.8\%) into acetonitrile.

Electrolysis was done at a constant potential under $\mathrm{Ar}$ (purity: 99.9999\%) atmosphere until total electricity reached $5 \mathrm{C}$. The products in liquid and gas phase were analyzed using GC-MS (Shimazu: QPMS-5000) equipped with capillary column (J\&W DB-1) and gas chromatogram (Shimazu: GC-3 BT), respectively.

\section{Results and Discussion}

At first, we searched the condition for studying the effect of water concentration on the dechlorination of chlorobenzene. Chlorobenzene $(0.010 \mathrm{M})$ was electrolyzed at $-3.01,-3.17$ and $-3.27 \mathrm{~V}$ in $0.1 \mathrm{M} \mathrm{TEAP/acetonitrile}$ containing $0.500 \mathrm{M} \mathrm{H}{ }_{2} \mathrm{O}$. The partial current density of benzene $j_{\mathrm{C} 6 \mathrm{H} 6}$ is enhanced with the increase of the negative potentials. At $-3.27 \mathrm{~V}$, however, the current efficiency of methane got higher. Control experiments without chlorobenzene verified that methane is produced from decomposition of the electrolytic solution. Thus, we did the electrolyses at $-3.17 \mathrm{~V}$ afterwards.

Chlorobenzene was electrolyzed at $-3.17 \mathrm{~V}$ in $0.1 \mathrm{M}$ TEAP/acetonitrile containing various concentrations of chlorobenzene between 0.010 and $0.200 \mathrm{M}$. The water concentration was controlled at $0.500 \mathrm{M}$. The value of $j_{\mathrm{C}_{6} \mathrm{H} 6}$ is enhanced linearly with the increase of the benzene concentration, reaching $167 \mathrm{~mA} \mathrm{~cm}^{-2}$ at $0.200 \mathrm{M}$ (Fig. 1). This current density is high enough for an industrial electrolysis. The current efficiency of hydrogen 
due to the water decomposition was less than $1 \%$ at $0.200 \mathrm{M}$ chlorobenzene, although the concentration of water is rather high $(0.500 \mathrm{M})$. No dimerized product such as biphenyl was detected.

We studied the effect of water concentration on the electrolysis of chlorobenzene at $-3.17 \mathrm{~V}$ in $0.1 \mathrm{M}$ TAEP /acetonitrile containing $0.200 \mathrm{M}$ chlorobenzene. Table 1 shows the results of the electrolyses at various water concentrations between $0.010 \mathrm{M}$ and $1.000 \mathrm{M}$.

The value of $j_{\mathrm{C} 6 \mathrm{H} 6}$ does not depend on the water concentration as shown in Fig. 2. This result differs from that of chloroform where the partial current density of the reduction product is enhanced with the increase of the water concentration. ${ }^{1}$

The total current efficiency is less than $85 \%$ at $\left[\mathrm{H}_{2} \mathrm{O}\right]$ more than $0.5 \mathrm{M}$ (Table 1). The products in the liquid phase were analyzed using GC-MS equipped with a capil-

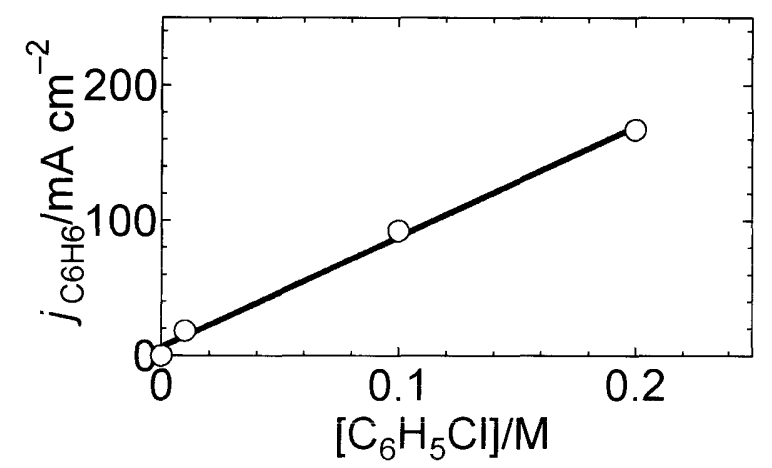

Fig. 1 Partial current density of benzene $(j(x)$ plotted against the concentration of chlorobenzene. Chlorobenzene is electrolyzed at $-3.17 \mathrm{~V}\left(\mathrm{FC} \mathrm{F}^{-}\right)$in $0.1 \mathrm{M}$ TEAP acetonitrile containing $0.500 \mathrm{M}$ water.

Table 1 Electrolysis of $0.200 \mathrm{M}$ chlorobenzene on silver electrode at various concentrations of water at $-3.17 \mathrm{~V}(\mathrm{Fc} /$ $\mathrm{Fc}^{+}$) in $0.1 \mathrm{M} \mathrm{TEAP/acetonitrile.}$

\begin{tabular}{ccccc}
\hline & \multicolumn{2}{c}{ Current efficirncy/\% } & \multicolumn{2}{c}{$j_{\mathrm{p}} / \mathrm{mA} \mathrm{cm}^{-2}$} \\
\hline$\left[\mathrm{H}_{2} \mathrm{O}\right] / \mathrm{M}$ & $\mathrm{C}_{6} \mathrm{H}_{6}$ & $\mathrm{H}_{2}$ & $\mathrm{C}_{6} \mathrm{H}_{6}$ & $\mathrm{H}_{2}$ \\
\hline 0.010 & 93.0 & 0.03 & 240 & 0.07 \\
0.030 & 89.7 & 0.02 & 262 & 0.05 \\
0.130 & 95.5 & 0.21 & 275 & 0.60 \\
0.500 & 82.1 & 0.74 & 167 & 1.50 \\
1.000 & 85.0 & 0.65 & 249 & 1.90 \\
\hline
\end{tabular}

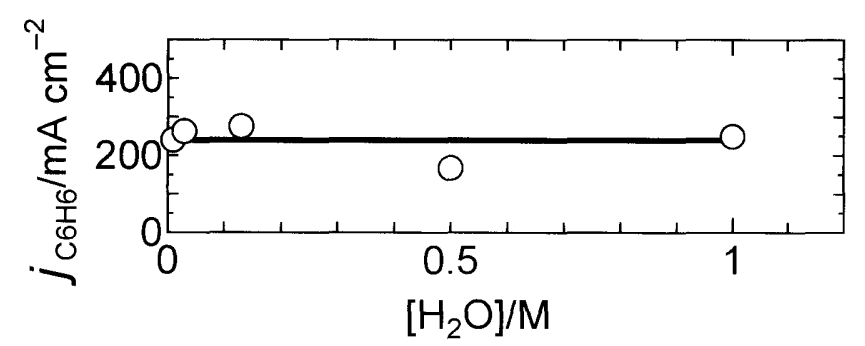

Fig. 2 Partial current density of benzene $\left(j_{\mathrm{C} 6 \mathrm{H} 6}\right)$ plotted against the concentration of water. Chlorobenzene $(0.200 \mathrm{M})$ is electrolyzed in $0.1 \mathrm{M} \mathrm{TEAP/acetonitrile} \mathrm{at}-3.17 \mathrm{~V}(\mathrm{Fc} /$ $\mathrm{Fc}^{+}$. lary column. We must remove the ionic species $\left(\left(\mathrm{C}_{2} \mathrm{H}_{5}\right)_{4}\right.$ $\mathrm{N}^{+}, \mathrm{ClO}_{4}^{-}$, etc.) in the electrolytic solution by vacuum evaporation before sampling, since non-volatile ionic species block the inside of the capillary column. More ionic products may be produced at higher water concentration; neglect of the ionic products may result in the low total current efficiency.

We electrolyzed $0.200 \mathrm{M}$ chlorobenzene at $-3.17 \mathrm{~V}$ in $0.1 \mathrm{M} \mathrm{TEAP/acetonitrile} \mathrm{containing} 1.000 \mathrm{M} \mathrm{D} \mathrm{D}_{2} \mathrm{O}$ to assess the proton source. The concentration of $\mathrm{H}_{2} \mathrm{O}$ was less than $0.002 \mathrm{M}$. Transmission IR spectra of TEAP/acetonitrile solution containing $\mathrm{D}_{2} \mathrm{O}$ showed no bands of $\mathrm{OH}$ stretching and bending vibration. This result supports that no hydrogen exchange occurs between $\mathrm{D}, \mathrm{O}$ and TEAP/acetonitrile solution. The partial current density of $\mathrm{C}_{6} \mathrm{H}_{5} \mathrm{D}$ was $49 \mathrm{~mA} \mathrm{~cm}^{-2}$, whereas that of $\mathrm{C}_{6} \mathrm{H}_{6}$ was 182 $\mathrm{mA} \mathrm{cm}{ }^{-2}$. This result indicates that the proton source is TEAP/acetonitrile as well as water. If the ratedetermining step of the reduction of chlorobenzene is the proton transfer reaction, the value of $j_{\mathrm{C} G \mathrm{H} 6}$ will be enhanced with the increase of the concentration of water. No dependence of $j_{\mathrm{C} 6 \mathrm{H} 6}$ on water concentration supports the model that the rate-determining step of the chlorobenzene reduction is the electron transfer process. ${ }^{12)}$

The selectivity $\mathrm{C}_{6} \mathrm{H}_{5} \mathrm{D} / \mathrm{C}_{6} \mathrm{H}_{6}\left(=j_{\mathrm{CH} \mathrm{H}_{51} \mathrm{D}} / j_{\mathrm{C} 6 \mathrm{H}}\right)$ for chlorobenzene is 0.27 . On the other hand, the selectivity for iodobenzene is 4.3 in the solution containing $1.000 \mathrm{M}$ $\mathrm{D}_{2} \mathrm{O}{ }^{1}$ ") These results, however, cannot be compared directly, because the electrode, potential and solvent in the electrolysis of iodobenzene differ from those of chlornbenzene.

Chlorobenzene was electrolyzed in the solution containing higher concentration of TEAP $(0.5 \mathrm{M})$ for the estimation of the effect of the supporting electrolyte on the electrolysis. The concentration of water was $1.000 \mathrm{M}$. The value of $j_{\mathrm{C} 6 \mathrm{H} 6}$ is $249 \mathrm{~mA} \mathrm{~cm}^{-2}$ in $0.1 \mathrm{M} \mathrm{TEAP/aceto-}$ nitrile (Table 1 ). In $0.5 \mathrm{M}$ TEAP solution, however, $j_{\mathrm{C} 6 \mathrm{H}}$ decreased down to $177 \mathrm{~mA} \mathrm{~cm}{ }^{-2}$. Studies using infrared reflection absorption spectroscopy show that tetraethylammonium cation is not adsorbed on electrode in acetonitrile solution, ${ }^{13}$ ) but tetraethylammonium cation affects the double layer structure. ${ }^{14}$ More tetraethylammonium cation may be accumulated around the electrode surface at higher concentration of TEAP, preventing the approach of chlorobenzene to the electrode. It is not probable that TEAP contributes to the reduction of chlorobenzene. From this result, acetonitrile may be the proton source other than water.

\section{Acknowledgement}

This work is partly supported by Grant-in-Aid for Scientific Research "No. 14550785" from the Ministry of Education and Science, Japan and Asahi Glass Foundation.

\section{References}

1) P. L. Cabot, M. Centelles, L. Segarra, and J. Casado, J. Electrochem. Soc., 144, 3749 (1997).

2) A. I. Tsyganok and K. Otsuka, Electrochim. Acta, 43, 2589 (1998). 
3) A. Kotsinaris, G. Kyriacou, and Ch. Lambrou, J. Appl. Electrochem., 28, 613 (1998).

4) Y. Hori, K. Murata, and T. Oku, Chem. Lett., 2003, 230.

5) H. Kiesele and J. Heinze, Organic Electrochemistry $3^{\text {rd }}$ eds, (Eds. H. Lund and M. M. Baizer), Dekker, New York, Chap. 7 (1990).

6) C. K. Mann and K. K. Barnes, Electrochemical Reactions in Nonaqueous Systems, Dekker, New York, Chap. 7 (1970).

7) O. Kargina, B. MacDougall, Y. M. Kargin, and L. Wang, J. Electrochem. Soc., 144, 3715 (1997).

8) N. Hoshi, K. Sasaki, S. Hashimoto, and Y. Hori, J. Electroanal. Chem., 568, 267 (2004).
9) J. R. Cockrell and R. W. Murray J. Elactrochem. Soc., 119, 849 (1972).

10) R. A. de la Torre and J. W. Sease, J. Am. Chem. Soc., 101, 1687 (1979)

11) F. M'Halla, J. Pinson, and J. M. Saveant, J. Am. Chem. Soc., 102, 4120 (1980).

12) J. M. Dumas-Bouchiat and J. M. Saveant, J. Am. Chem. Soc., 101, 3431 (1979).

13) N. S. Marinković, M. Hecht, J. S. Loring, and W. R. Fawcett, Electrochim. Acta, 41, 641 (1996).

14) M. R. Anderson and J. Huang, J. Electroanal. Chem., 318, 335 (1991). 